\title{
ULTIMATE LOAD-BEARING CAPACITY OF SELF-ANCHORED SUSPENSION BRIDGES
}

\section{Chin-Sheng Kao}

Department of Civil Engineering, Tamkang University, 151 Ying-chuan Road, Tamsui, Taipei County 25137, Taiwan, R.O.C

Chang-Huan Kou

Department of Civil Engineering and Engineering Informatics, Chunghua University, 707, Sec. 2, Wu-fu Road, Hsinchu City 30012, Taiwan, R.O.C, chkou@chu.edu.tw

Wen-Liang Qiu

Department of Civil Engineering, Dalian University of Technology, No. 2 Linggong Road, Ganjingzi District, Dalian City, Liaoning Province, 116024, China, P.R.C

Jeng-Lin Tsai

Department of Civil Engineering and Engineering Informatics, Chunghua University, 707, Sec. 2, Wu-fu Road, Hsinchu City 30012, Taiwan, R.O.C.

Follow this and additional works at: https://jmstt.ntou.edu.tw/journal

Part of the Civil and Environmental Engineering Commons

\section{Recommended Citation}

Kao, Chin-Sheng; Kou, Chang-Huan; Qiu, Wen-Liang; and Tsai, Jeng-Lin (2012) "ULTIMATE LOAD-BEARING CAPACITY OF SELF-ANCHORED SUSPENSION BRIDGES," Journal of Marine Science and Technology. Vol. 20: Iss. 1, Article 3. DOI: $10.51400 / 2709-6998.2418$

Available at: https://jmstt.ntou.edu.tw/journal/vol20/iss1/3

This Research Article is brought to you for free and open access by Journal of Marine Science and Technology. It has been accepted for inclusion in Journal of Marine Science and Technology by an authorized editor of Journal of Marine Science and Technology. 


\title{
ULTIMATE LOAD-BEARING CAPACITY OF SELF-ANCHORED SUSPENSION BRIDGES
}

\author{
Chin-Sheng $\mathrm{Kao}^{1}$, Chang-Huan $\mathrm{Kou}^{2}$, Wen-Liang Qiu${ }^{3}$, and Jeng-Lin Tsai ${ }^{2}$
}

Key words: suspension bridge, self-anchored, ultimate load-bearing, broken cable.

\begin{abstract}
This paper presents a method of reduced stiffness coupled with step increments to simulate the nonlinear problem that occurs when a material is in the elasto-plastic stage. A set of equations was developed and used to analyze the ultimate loadbearing capacity and the failure process of a self-anchored suspension bridge. Also investigated here were the effects on the load-bearing capacity due to variations in the strength and stiffness of the four substructures and due to broken hangers. The results showed that variations in the material strength and the structural stiffness of the substructures can lead to different degrees of influence on the ultimate load-bearing capacity of the self-anchored suspension bridge. Further, broken hangers have a significant effect on the ultimate load-bearing capacity and can lead to the collapse of the suspension bridge under its own weight when many are broken at the same time.
\end{abstract}

\section{INTRODUCTION}

Due to the larger span length and its elegant structural shape, the suspension bridge is often seen as a landmark and favored in the construction of a bridge that crosses a river. The main cables of self-anchored suspension bridge are anchored at the ends of the main girder instead of at the two earth-anchored structures, saving construction costs and space. In addition, the axial force in the main cable can be effectively turned into a cost-free pre-stress for a main concrete girder, so that the design of the cross-section of the reinforced concrete girder is optimized. Therefore, the self-anchored suspension bridge should be investigated and its advantages publicized. Making

Paper submitted 01/14/10; revised 07/01/10; accepted 07/08/10. Author for correspondence: Chang-Huan Kou (e-mail: chkou@chu.edu.tw).

${ }^{1}$ Department of Civil Engineering, Tamkang University, 151 Ying-chuan Road, Tamsui, Taipei County 25137, Taiwan, R.O.C.

${ }^{2}$ Department of Civil Engineering and Engineering Informatics, Chunghua University, 707, Sec. 2, Wu-fu Road, Hsinchu City 30012, Taiwan, R.O.C.

${ }^{3}$ Department of Civil Engineering, Dalian University of Technology, No. 2 Linggong Road, Ganjingzi District, Dalian City, Liaoning Province, 116024, China, P.R.C. use of the ultimate load-bearing characteristics, the ultimate strength of the bridge can be better understood and the factors influencing the safety of the bridge can be identified. This paper presents an algorithm that was used to analyze and investigate the ultimate load-bearing characteristics of selfanchored suspension bridges. The information related to the mechanical properties of the self-anchored suspension bridge will be helpful to academic and engineering communities.

In the ultimate load-bearing analysis, a finite element analysis of an arch bridge based on nonlinear geometrical and material properties was performed by Komatsu and Sakimoto [5]. They proposed an elasto-plastic model to obtain the ultimate load-bearing capacity of a cable-stayed bridge. They also suggested that the instability value of the bifurcation limit point should be used to determine the failure of the cable-stayed bridge. In addition to determining the ultimate load-bearing coefficients for the cable-stayed bridge, Ren also investigated the effect of an auxiliary pier using a model that accounts for nonlinear geometry and material properties, and conducted an ultimate behavior analysis of a $200 \mathrm{~m}$ span, concrete cablestayed bridge [7]. The results showed that it did not lead to instability for the whole bridge, but buckling of members occurred. Seif and Dilger [8] On the other hand, derived equations that account for nonlinear geometry using updated Lagrangian formulation. They performed a full process nonlinear analysis for the construction stage and service stage of suspension bridge, and gave the relationship between load and deformation. Wang and Yang [10] considering both geometrical and material nonlinearities, analyzed the ultimate loadbearing capacity of a large-span bridge. In their paper, the UL method was adopted for the geometric nonlinearity and the layered finite element method was used for the material nonlinearity. Pan and Jang [6] briefly introduced a FEM method for a plane truss system with nonlinear geometry and performed a geometric and material nonlinear analysis of a reinforced concrete arch bridge. The results derived from an analysis considering both geometric and material nonlinearities agreed with the experimental values very well. They also mentioned that the ultimate load-bearing capacity of an arch bridge was mainly affected by the material nonlinearity. Feng and Wang [2] then used the updated Lagrangian formulation to derive elasto-plastic equations for calculating the ultimate bearing load of a cable-stayed bridge. In the derivation, the effects of sagging, geometric and material nonlinearities of the 
beam were considered. The results showed that the ultimate load-bearing coefficient obtained using elasticity was by far higher than that obtained via elasto-plastic analysis. Shiu [9] used a FEM with incremental stiffness to perform a plastic structural analysis of a 2D cable-stayed bridge and investigated the effect of plastic properties on the behavior of the cable-stayed bridge. Ye [11] Investigated the ultimate behavior of a long-span steel arch bridge using three methods (linear buckling, geometrically nonlinear buckling and geometrically and materially nonlinear buckling). Cheng and Jiang [1] primarily studied the ultimate load-carrying capacity of a self-anchored concrete suspension bridge. Jiang and Qiu [3] finally, investigated the effect of broken hangers on the ultimate load-bearing capacity of a large-spanned cable-stayed bridge based on a 3D elasto-plastic finite deformation theory of thin-walled structures [4].

This paper presents a method of reduced stiffness coupled with step increments to simulate the nonlinear problem that occurs when the material is in the elasto-plastic stage. A set of equations was developed and used to analyze the ultimate loadbearing capacity and the failure process of a self-anchored suspension bridge. Also those investigated here were the effects on the load-bearing capacity of the self-anchored suspension bridge due to variations in the strength and stiffness of the four substructures: the main cable, hanger, tower, and main girder, and due to broken hangers.

\section{THEORETICAL ANALYSIS}

\section{Basic Assumptions}

(1) The effects of shear stress and shear strain are neglected.

(2) There are no slips between the reinforced steel and concrete.

(3) The average stiffness of the element is taken as the element stiffness.

(3) Plane sections remain plane, i.e. the strain distribution on any section at any time is linear along the main girder height. The reinforced steel and concrete are both elastoplastic with stress-strain relationships given by $\sigma_{s}=\sigma_{s}(\varepsilon)$ and $\sigma_{c}=\sigma_{c}(\varepsilon)$.

\section{The Reduced Stiffness Method}

When the member is in the elastic-plastic state, the flexural stiffness, $E I$, and the axial stiffness, $E A$, of the cross-section will vary with increasing load. For a small material element subjected to small load increments, the relations between the bending moment, axial force, flexural stiffness, EI, and axial stiffness, EA, are given below:

$$
\left\{\begin{array}{l}
M=-\xi E I \chi=-C \chi \\
N=\eta E A \varepsilon=B \varepsilon
\end{array}\right.
$$

where $M$ and $N$ are the bending moment and axial force acting on the cross-section respectively; $\xi, \eta$ are the reduction coef- ficients for bending and axial stiffness respectively; $\chi, \varepsilon$ are the curvature and axial strain at the geometric center of the cross-section respectively; $C, B$ are the bending and axial reduced stiffness respectively.

In the structural analysis of ultimate loading carrying capacity, $N_{i}$ and $M_{i}$ are the axial force and moment applied to the element during the step of the loading process respectively, with corresponding reduced stiffness denoted by $B_{i}$ and $C_{i}$. The calculation procedure of $B_{i}$ and $C_{i}$ is described as follows:

Assuming that the axial strain and curvature at the geometric center of the cross-section are $\varepsilon_{i}^{(0)}=N / B_{i-1}$ and $\chi_{i}^{(0)}=$ $-M / C_{i-1}$ respectively, the cross-section of the reinforced concrete beam can be divided into $m_{\mathrm{c}}$ layers. Let the concrete area of the $j$ th layer be $A_{c j}$, then the strain at the centroid of the $j$ th layer is

$$
\varepsilon_{c j}=\varepsilon_{i}^{(0)}+y_{c j} \chi_{i}^{(0)}
$$

where $y_{c j}$ denotes the distance from the centroid of the $j$ th layer to the centroid of the cross-section.

The stress for each layer, $\sigma_{c i}$ can be determined from the stress-strain relation for the concrete. The axial force acting on that layer is

$$
P_{c j}=\sigma_{c j} A_{c j}=\sigma\left(\varepsilon_{c j}\right) A_{c j}
$$

Similarly, it is assumed that there are $m_{\mathrm{s}}$ layers of reinforcing steel in the beam cross-section. The area of the $j$ th steel layer is $A_{s j}$ whereas the distance from the centroid of the layer to that of the cross-section is $y_{s j}$. The stress, strain, and axial force acting on the centroid of the steel layer are

$$
\begin{gathered}
\sigma_{s j}=\sigma_{s}\left(\varepsilon_{s j}\right) \\
\varepsilon_{s j}=\varepsilon_{i}^{(0)}+y_{s j} \chi_{i}^{(0)} \\
P_{s j}=\sigma_{s j} A_{s j}
\end{gathered}
$$

Thus, corresponding to $\varepsilon_{i}^{(0)}$ and $\chi_{i}^{(0)}$, the total axial force and moment acting on the cross-section of the beam are

$$
\begin{gathered}
N_{P}=\sum_{j=1}^{m_{c}} P_{c j}+\sum_{j=1}^{m_{s}} P_{s j}=\sum_{j=1}^{m_{c}} \sigma_{c j} A_{c j}+\sum_{j=1}^{m_{s}} \sigma_{s j} A_{s j} \\
M_{P}=\sum_{j=1}^{m_{c}} P_{c j} y_{c j}+\sum_{j=1}^{m_{s}} P_{s j} y_{s j}=\sum_{j=1}^{m_{c}} \sigma_{c j} A_{c j} y_{c j}+\sum_{j=1}^{m_{s}} \sigma_{s j} A_{s j} y_{s j}
\end{gathered}
$$

Let $\Delta N=N_{P}-N, \Delta M=M_{P}-M$. If $\Delta N$ and $\Delta M$ are less than or equal to the pre-assigned allowable error, then the previous $\varepsilon_{i}^{(0)}$ and $\chi_{i}^{(0)}$ are considered to be accurate and the solution has thus been obtained. Otherwise, the values of $\varepsilon_{i}^{(0)}$ and $\chi_{i}^{(0)}$ must be adjusted through an iterative procedure until $\Delta N$ and $\Delta M$ 


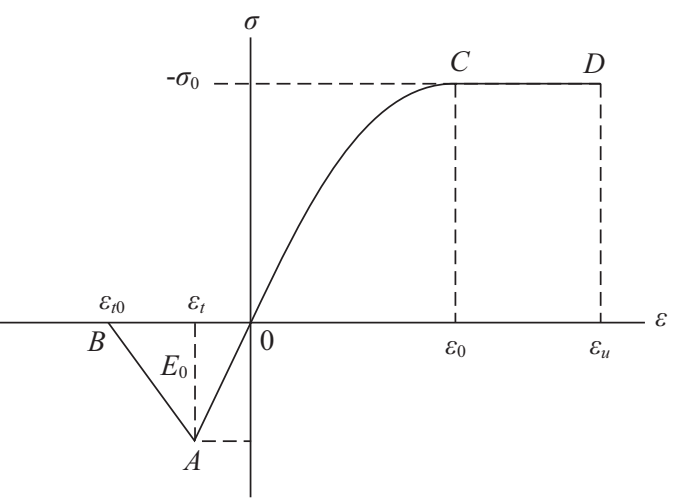

Fig. 1. The stress-strain relationship of concrete.

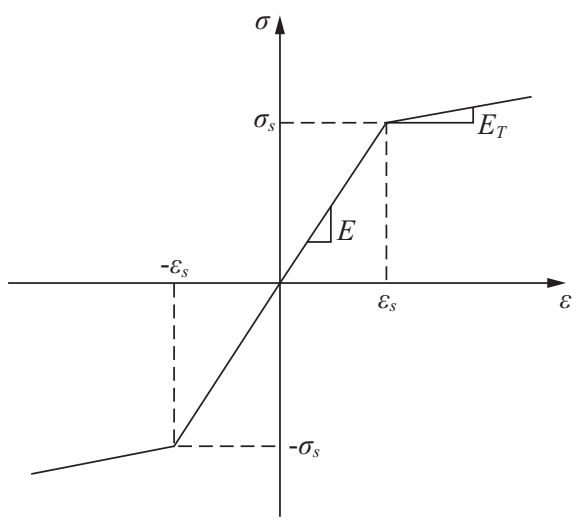

Fig. 2. The stress-strain relationship of reinforced steel.

are smaller than the pre-assigned allowable error. Finally, the reduced stiffness for the cross-section can be determined as:

$$
\left\{\begin{array}{l}
B_{i}=N / \mathcal{E}_{i}^{(n)} \\
C_{i}=-M / \chi_{i}^{(n)}
\end{array}\right.
$$

\section{The Stress-Strain Relationship of Material}

Fig. 1 shows the stress-strain relationship of the concrete, where $\sigma_{0}=0.85 \cdot f_{c k}$ and $f_{c k}$ is the concrete compressive strength determined from standard cylindrical specimen, $\varepsilon_{0}=$ -0.002 , and the limit compressive strain is $\varepsilon_{u}=0.0035$.

Fig. 2 shows the stress-strain relationship of reinforced steel, where $\varepsilon_{S}$ is the yield strain, $E$ and $E_{T}$ are the elastic modulus before and after the yield point.

Fig. 3 shows the stress-strain relationship of the main cable and hanger, whereby $\varepsilon_{s}$ is the yield strain corresponding to the yield stress, $\sigma_{s}=0.84 \sigma_{p u}$ and $\sigma_{p u}$ is the ultimate strength of the steel wire.

\section{STRUCTURAL ANALYSIS}

\section{Basic Information for Structural Analysis}

A self-anchored concrete suspension bridge with two towers, two cable planes and three spans is analyzed herein.

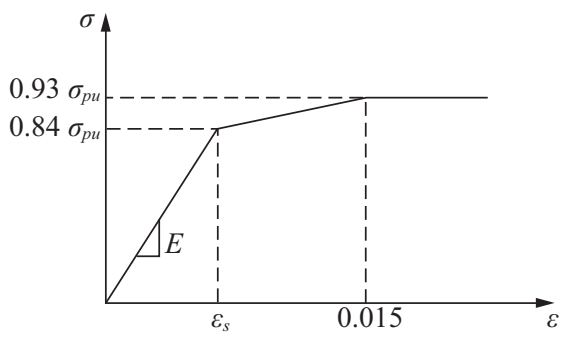

Fig. 3. The stress-strain relationship of main cable and hangers.

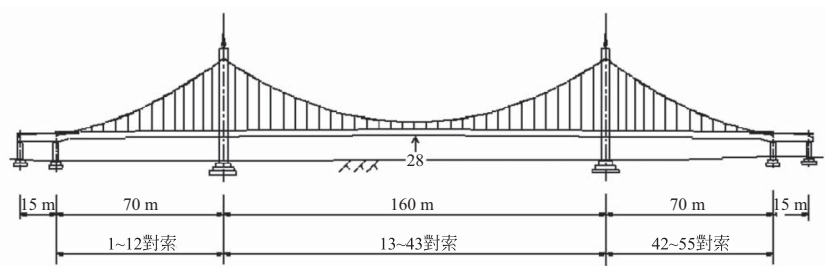

(a)

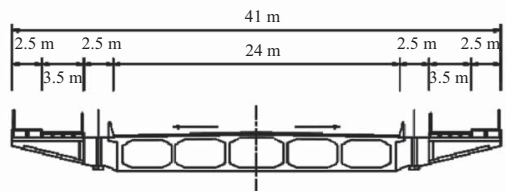

(b)

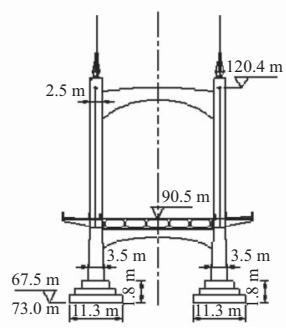

(c)

Fig. 4. (a) Side view, (b) cross-section of main girder, (c) view of bridge tower.

The whole suspension bridge is shown in Fig. 4. The total length of the bridge was $300 \mathrm{~m}$; the main span had the length of $160 \mathrm{~m}$ and each of the two side spans had a length of $70 \mathrm{~m}$. The main girder was a reinforced concrete box girder with a width of $24 \mathrm{~m}$ and height of $2.5 \mathrm{~m}$. On the other hand, the standard compressive strength of the concrete was $35 \mathrm{MPa}$ and the yield strength of the reinforcing steel was $340 \mathrm{MPa}$. The H-shaped tower had a height of $42.4 \mathrm{~m}$ with solid rectangular cross-sections. The cross-sectional dimensions were $2.5 \mathrm{~m} \times 3.5 \mathrm{~m}$ above the deck, but differed below the deck with dimensions of $4.06 \mathrm{~m} \times 3.5 \mathrm{~m}$ at the bottom. The foundation was spread footing in bedrock and the dimensions at the bottom of the foundation were $11.3 \mathrm{~m} \times 11.3 \mathrm{~m}$. The rise-span ratio of the main cable was $1 / 6$. The spacing between two hangers was $5 \mathrm{~m}$, and the number of hangers in each cable plane was 55. The ultimate strength of the main cable and hanger wires were $1960 \mathrm{MPa}$ and $1670 \mathrm{MPa}$ respectively. The primary structural parameters of the main girder, tower, main cable, and hangers are shown in Table 1. 
Table 1. Primary parameters of the self-anchored suspension bridge.

\begin{tabular}{|c|c|c|c|c|c|}
\hline Structure element & $\mathrm{A}\left(\mathrm{m}^{2}\right)$ & Ix $\left(m^{4}\right)$ & $\operatorname{Iy}\left(m^{4}\right)$ & $\mathrm{Iz}\left(\mathrm{m}^{4}\right)$ & $\mathrm{E}\left(\mathrm{N} / \mathrm{m}^{2}\right)$ \\
\hline Main girder & 16.41 & 50.40 & 15.00 & 896.18 & $3.5^{*} 10^{10}$ \\
\hline Tower & 13.67 & 28.03 & 19.38 & 14.47 & $3.5^{*} 10^{10}$ \\
\hline Main cable & 0.12 & - & - & - & $1.3^{*} 10^{11}$ \\
\hline Hanger & 0.0047 & - & - & - & $1.95 * 10^{11}$ \\
\hline
\end{tabular}

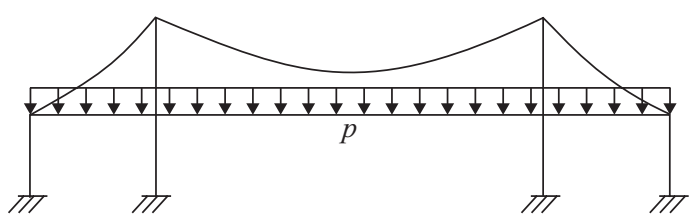

Fig. 5. The loading model.

The ANSYS finite element software and a plane finite element model are used to investigate the ultimate loadbearing characteristics of the self-anchored suspension bridge. The finite element model is shown in Fig. 4(a). Beam elements were used to simulate the tower columns, the piers and the main girders. The main cables and hangers were modeled as truss elements. The saddles were also simulated as rigid arm elements and the foundations were simplified as spring models. The analysis considered the effects of large displacement in the main cables and hangers and the rigidity at initial loading.

\section{Model for Analysis}

For the design of the main girder, the static load was $P_{d}=$ $783.4 \mathrm{kN} / \mathrm{m}$ and the live load was $P_{l}=81.6 \mathrm{kN} / \mathrm{m}$ with a total design load of $P_{d}+P_{l}=865.0 \mathrm{kN} / \mathrm{m}$. The following loading process was adopted. First, an analysis was performed on the bridge subjected to static load only. Then, structural analysis was performed with a uniformly distributed load of $P=(L-$ 1) $P_{d}$ applied to the main girder. Analysis continued until the bridge failed. The loading model is shown in Fig. 5 and the sum of the static load and the uniformly distributed load, $P$ acting on the main girder was $L \cdot P_{d}$, where $L$ is a loading coefficient.

\section{The Structural Failure Mode}

In this study, the structure is considered to have reached failure if, during the loading process, concrete strain on any cross-section of the main girders or of the tower reaches the ultimate strain $\varepsilon_{u}$; or if the stress in any main cables or hanger cables reaches $0.93 \sigma_{p u}$; or if the total stiffness of the structure as a whole decreases to a level that further loading is not possible without causing structural instability. The maximum loading $L_{\max } \cdot P_{d}$ that can be withstood by the structure at this point of failure is the elastic-plastic ultimate load-bearing capacity of the structure.

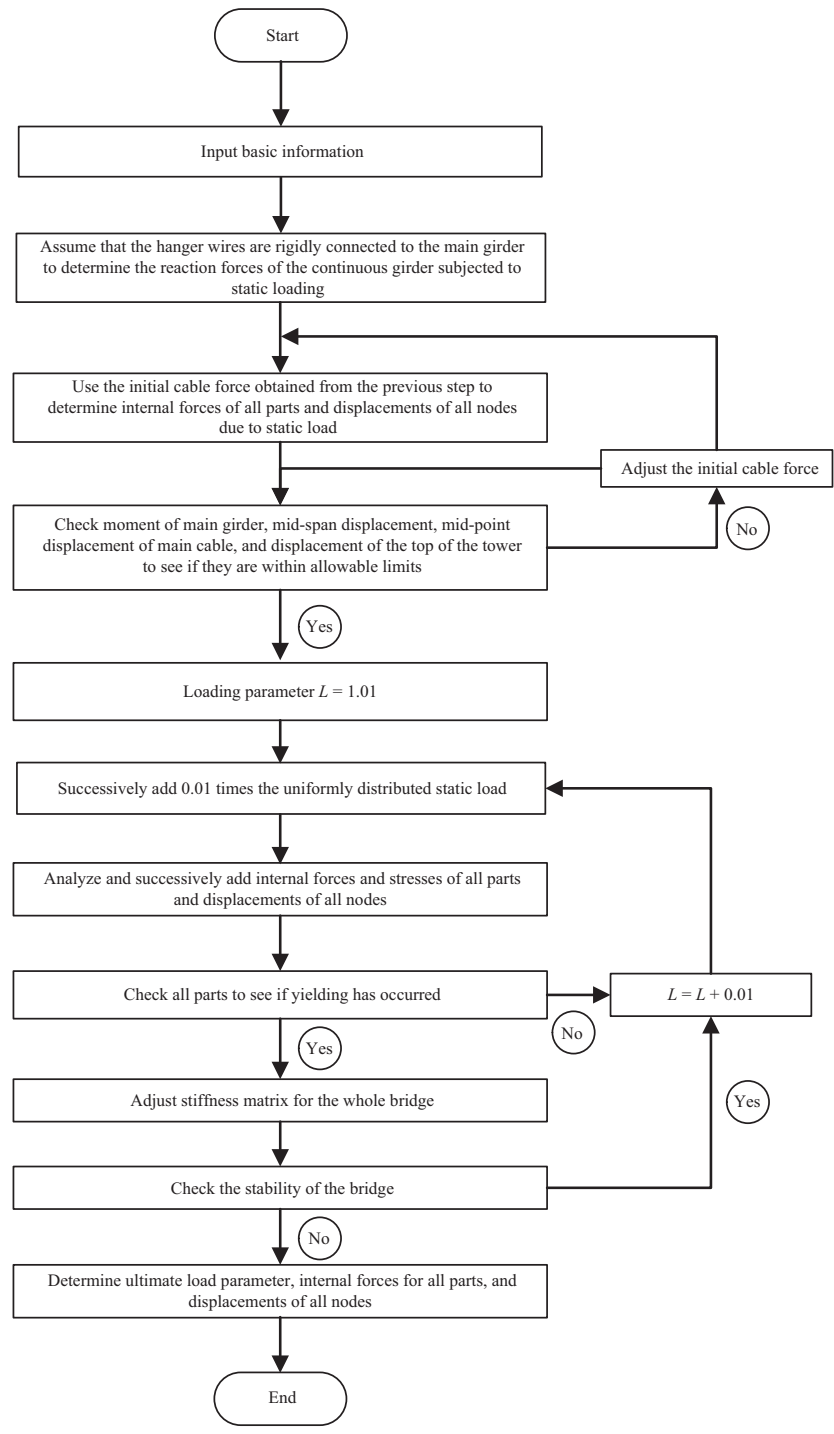

Fig. 6. Flow chart for ultimate load-bearing capacity analysis for a selfanchored suspension bridge.

\section{Procedure of the Analysis}

A structural analysis of the initial state was first performed on the whole bridge using only the static load. Then, using a self-developed program based on the reduced stiffness method and an iterative process, analysis was performed to determine the ultimate load capacity and the failure process for the selfanchored suspension bridge. The analysis process is shown in Fig. 6.

\section{RESULTS AND DISCUSSIONS}

\section{Ultimate Load-Bearing Capacity and Failure Process}

For the self-anchored suspension bridge considered in this paper, the ultimate load-bearing coefficient has been found to be $L=3.18$ when the main girder was loaded both on the main span and on the side spans. This implies that when the bridge 


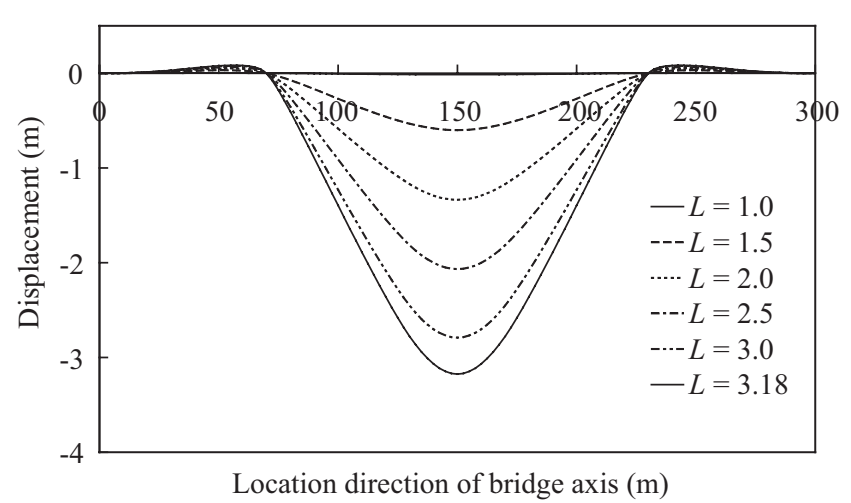

Fig. 7. Vertical displacements along the longitudinal direction of main girder.

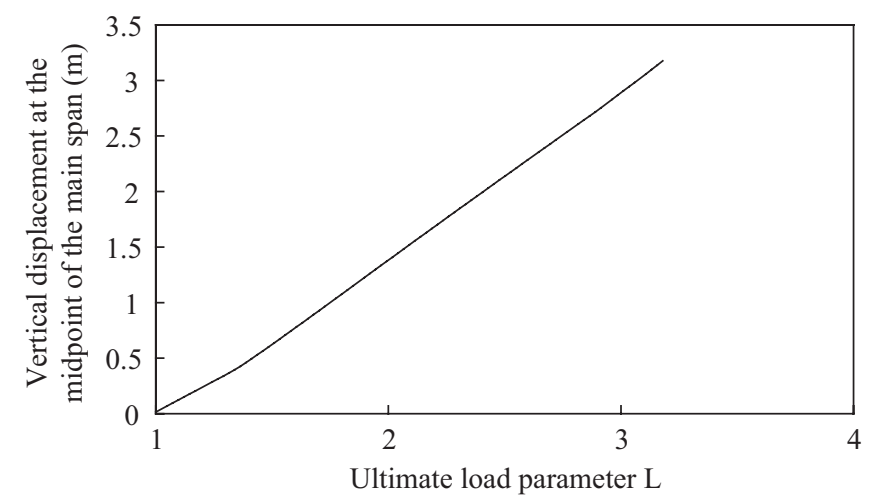

Fig. 8. Vertical displacements at the mid-point of the mid-span of main girder.

was loaded on the main girder with the uniformly distributed load, its maximum uniform loading was 3.18 times the static load. Furthermore, after the loading of $(L-1) P_{d}$ with increasing $L$, the bridge was gradually damaged. When $L=1.29$, cracks occurred in the concrete at the upper edge of the main girder located near the tower. When $L=1.36$, the concrete at the lower edge of the main span started to crack; when $L=$ 1.65 , the concrete at the bottom of the tower started to crack; when $L=1.93$, the concrete in the bridge tower at the height of main girder started to crack; when $L=2.89$, the stress in the No. 28 hanger reached its yield stress; and when $L=3.18$, the No. 28 hanger reached its ultimate strength and the whole suspension bridge failed.

Moreover, when the main girder was only loaded on the main span, the ultimate load-bearing coefficient $L=2.87$, and the failure process of the suspension bridge are as follows: when $L=1.35$, concrete at the bottom of the main span started to crack; when $L=1.37$, concrete on the upper surface of main girder in the side span began to crack and cracks continued to propagate as the loading increased; when $L=1.53$, concrete at the bottom of the bridge tower started to crack; when $L=2.60$, the stress in hanger cable No.1 reached the yielding stress; when $L=2.77$, hanger cable No. 28 also reached the yielding stress; and finally, by $L=2.87$, hanger cable No. 1 reached

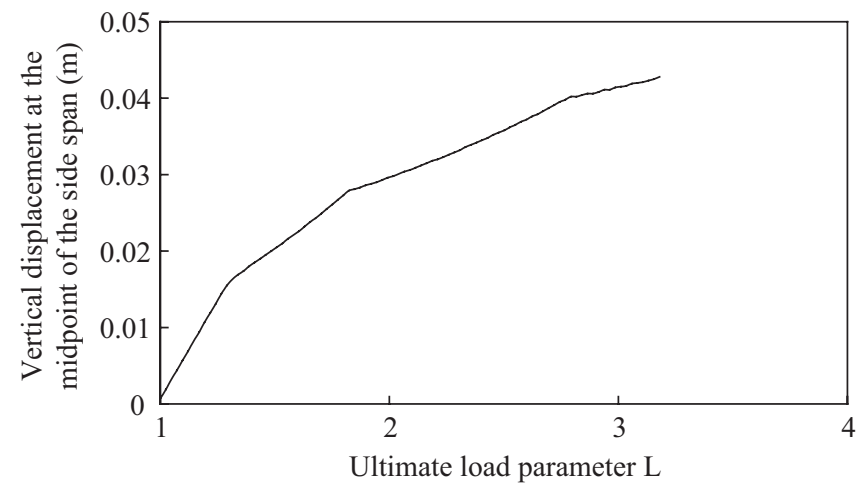

Fig. 9. Vertical displacements at the mid-point of the side-span of main girder.

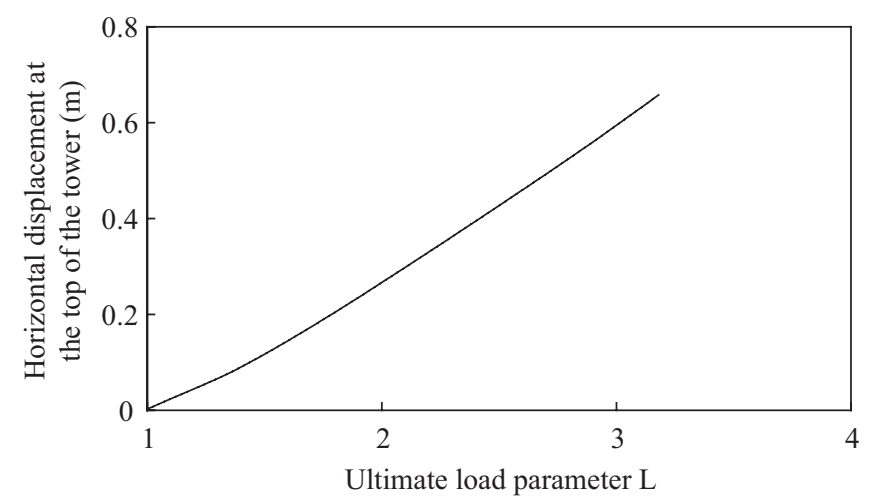

Fig. 10. Horizontal displacements at the top of the tower.

ultimate stress, causing the whole suspension bridge to be at ultimate failure.

\section{Structural Response}

To show the reactions of the main components of the bridge structure, i.e. main girder, bridge tower, hangers, and the main cables, during the failure process of the suspension bridge, the displacements of the main girder and tower at each value of loading coefficient are shown in Figs. 7-10. The cable forces for the hangers and the main cable are also shown in Figs. 11-12 for various values of loading coefficients. Figs. 7-10 show that the deformations of the main girder and the tower were nonlinearly related to the loading coefficient. On the other hand, Figs. 11 and 12 show the cable force distributions for the hangers and main cable at the state of $L=1.0$ and the ultimate state of $L=3.18$. Fig. 13 show the moment for the main girder at $L=3.18$.

\section{The Effects of Varying Strength of the Main Components}

\section{1) The Effects on the Ultimate Load-Carrying Capacity}

Table 2 shows the calculated results for the ultimate loadbearing coefficient when the material strength of each of the four components of the self-anchored suspension bridge, i.e. 
Table 2. Ultimate load-bearing coefficient when the material strength of the components was halved.

\begin{tabular}{ccc}
\hline Item & & Ultimate load-bearing coefficient \\
\hline \multirow{3}{*}{$\begin{array}{c}\text { Strength } \\
\text { reduced by a half }\end{array}$} & Main cable & 2.11 \\
\cline { 2 - 3 } & Hanger & 1.89 \\
\cline { 2 - 3 } & Main girder & 2.91 \\
\cline { 2 - 3 } & Tower & 3.12 \\
\hline
\end{tabular}

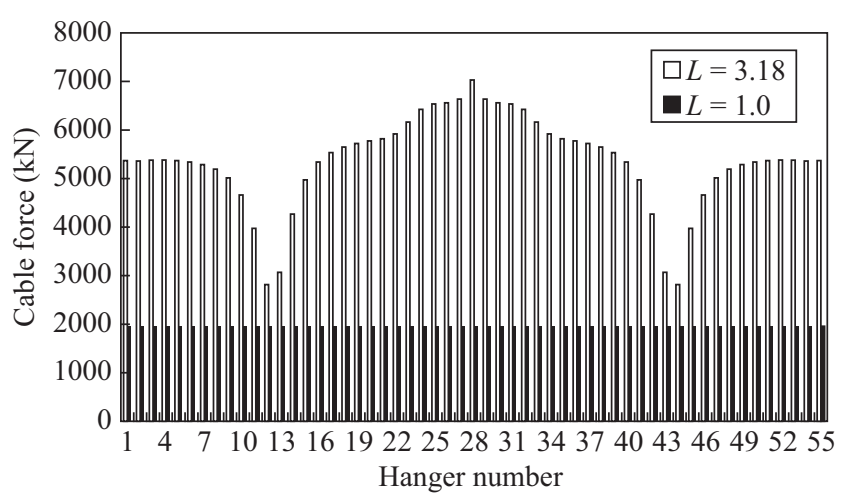

Fig. 11. Tension forces of the hangers.

main cable, hangers, main girder, and the bridge tower, was halved. It is shown that the ultimate load-carrying capacity was affected the most by the reduction in strength of the hanger, then the reduction in main cable strength, then the main girder strength, and finally the reduction in strength of the tower.

\section{2) The Effects on the Failure Process}

When the strength of the main cable was halved, the stress in the main cable near the tower reached the yield stress value at $L=1.88$; and when $L=2.11$, the stress at this position reached the ultimate stress value and the whole suspension bridge failed.

When the strength of the hangers were reduced by half, the stress in the No. 28 hanger reached the yield stress value of $L=$ 1.69 ; and when $L=1.89$, the stress in this hanger reached the ultimate stress value and the whole suspension bridge failed.

When the strength of the main girder was reduced by a half, a plastic hinge was formed at $L=1.99$ in the concrete on the top surface of the girder near the tower-girder connection; when $L=2.40$, a plastic hinge was formed at the mid-span of the main span; when $L=2.60$, the stress of the No. 28 hanger reached the yield stress value; and when $L=2.91$, the stress of the No. 28 hanger reached the ultimate stress value and the whole suspension bridge failed.

When the strength of the tower was reduced by half, a plastic hinge was formed at $L=2.36$ in the concrete of the tower near the tower-girder connection; when $L=2.86$, the stress of the No. 28 hanger reached the yield stress value; when $L=3.08$, a plastic hinge was formed in the concrete on

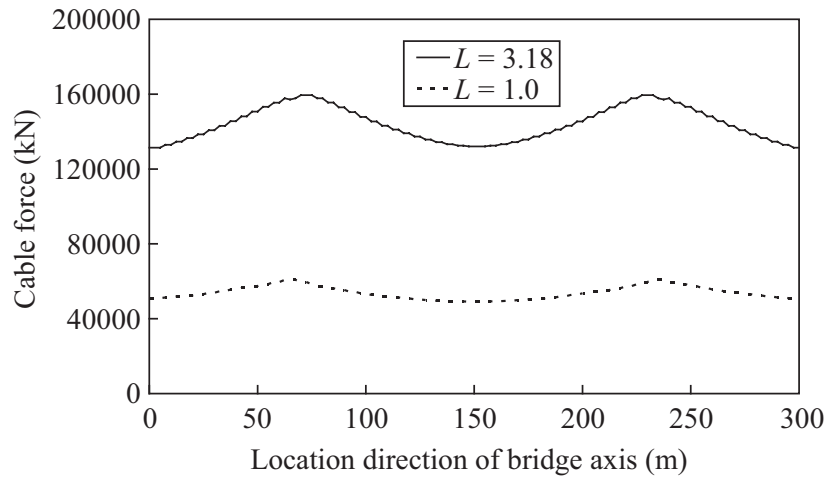

Fig. 12. Tension forces of main cable along the longitudinal direction of the bridge.

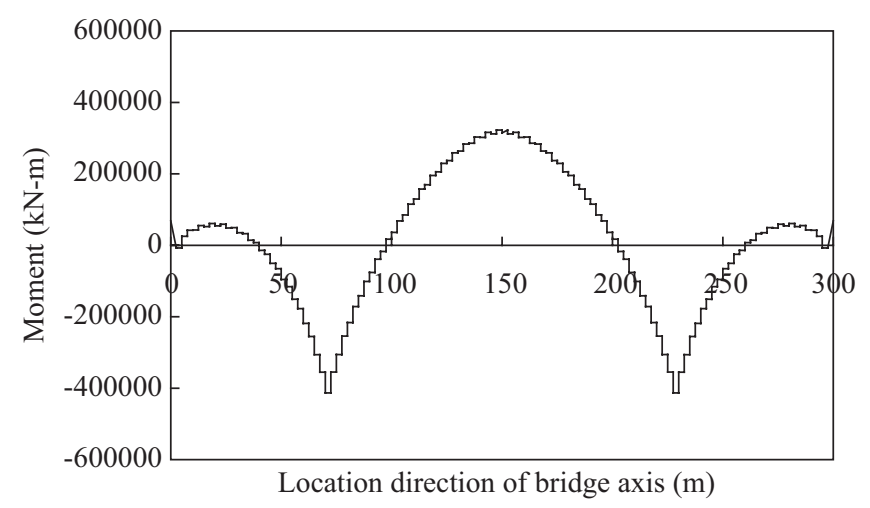

Fig. 13. Moments of the main girder along the longitudinal direction of the bridge when $L=3.18$.

the top surface of the girder near the tower-girder connection; and when $L=3.12$, the stress of the No. 28 hanger reached the ultimate stress value and the whole suspension bridge failed.

Summarizing the previous findings, it can be concluded that the final failure of the original suspension bridge occurred when the stress in the hanger at the mid-span of the bridge reached its ultimate strength value. Therefore, the hanger had the most detrimental effect on the ultimate load-bearing capacity of the bridge if its strength was reduced by half. Considering the main cable, it reached the yield and ultimate stresses before the hanger did. When the strength of the main girder was reduced by half, the stiffness of the main girder was reduced, which caused the hangers to carry extra loads leading to yielding and ultimate failure of the hangers. Therefore, the effect of the main girder was much more significant than that of the tower if its strength was reduced by half.

\section{The Effects Due to Variation of Stiffness of Main Components}

\section{1) The Effects on Ultimate Load-Bearing Capacity}

Table 3 shows the ultimate load-bearing coefficient from the analysis of the self-anchored suspension bridge when the 
Table 3. Ultimate load-bearing coefficient when the structural stiffness of the component was halved.

\begin{tabular}{ccc}
\hline & & Ultimate load-bearing coefficient \\
\hline \multirow{3}{*}{$\begin{array}{c}\text { Stiffness } \\
\text { reduced by a half }\end{array}$} & Main cable & 2.81 \\
\cline { 2 - 3 } & Hanger & 3.01 \\
\cline { 2 - 3 } & Main girder & 3.09 \\
\cline { 2 - 3 } & Tower & 3.17 \\
\hline
\end{tabular}

Table 4. Effect on internal forces due to halving the structural stiffness of the component $(L=2.0)$.

\begin{tabular}{|c|c|c|c|c|c|}
\hline Item & $\begin{array}{c}\text { Original } \\
\text { value }\end{array}$ & $\begin{array}{c}\text { Main cable } \\
\text { reduced } \\
\text { by a half }\end{array}$ & $\begin{array}{l}\text { Hanger } \\
\text { reduced } \\
\text { by a half }\end{array}$ & $\begin{array}{c}\text { Main } \\
\text { girder } \\
\text { reduced } \\
\text { by a half }\end{array}$ & $\begin{array}{c}\text { Bridge } \\
\text { tower } \\
\text { reduced } \\
\text { by a half }\end{array}$ \\
\hline $\begin{array}{l}\text { Main cable } \\
\text { force } \\
(\mathrm{kN})\end{array}$ & $\begin{array}{c}92193 \\
(100 \%)\end{array}$ & $\begin{array}{c}88481 \\
(-4.03 \%)\end{array}$ & $\begin{array}{c}91987 \\
(-0.22 \%)\end{array}$ & $\begin{array}{c}93154 \\
(1.04 \%)\end{array}$ & $\begin{array}{c}91341 \\
(-0.92 \%)\end{array}$ \\
\hline $\begin{array}{c}\text { Hanger } \\
\text { force } \\
(\mathrm{kN})\end{array}$ & $\begin{array}{c}3580 \\
(100 \%)\end{array}$ & $\begin{array}{c}3787 \\
(5.78 \%)\end{array}$ & $\begin{array}{c}3686 \\
(2.96 \%)\end{array}$ & $\begin{array}{c}3673 \\
(2.60 \%)\end{array}$ & $\begin{array}{c}3565 \\
(-0.42 \%)\end{array}$ \\
\hline $\begin{array}{l}\text { Axial force } \\
\text { in main } \\
\text { girder } \\
(\mathrm{kN})\end{array}$ & $\begin{array}{c}-159680 \\
(100 \%)\end{array}$ & $\begin{array}{l}-148487 \\
(-7.01 \%)\end{array}$ & $\begin{array}{l}-159635 \\
(-0.03 \%)\end{array}$ & $\begin{array}{l}-159664 \\
(-0.01 \%)\end{array}$ & $\begin{array}{l}-158623 \\
(-0.66 \%)\end{array}$ \\
\hline $\begin{array}{c}\text { Bending } \\
\text { moment of } \\
\text { main girder } \\
(\mathrm{kN}-\mathrm{m})\end{array}$ & $\begin{array}{l}178149 \\
(100 \%)\end{array}$ & $\begin{array}{c}204223 \\
(14.64 \%)\end{array}$ & $\begin{array}{c}178973 \\
(0.46 \%)\end{array}$ & $\begin{array}{c}158674 \\
(-10.93 \%)\end{array}$ & $\begin{array}{c}190684 \\
(7.04 \%)\end{array}$ \\
\hline $\begin{array}{c}\text { Axial force } \\
\text { in bridge } \\
\text { tower } \\
(\mathrm{kN})\end{array}$ & $\begin{array}{c}-220083 \\
(100 \%)\end{array}$ & $\begin{array}{l}-216084 \\
(-1.82 \%)\end{array}$ & $\begin{array}{l}-218781 \\
(-0.59 \%)\end{array}$ & $\begin{array}{l}-221282 \\
(0.54 \%)\end{array}$ & $\begin{array}{l}-218555 \\
(-0.69 \%)\end{array}$ \\
\hline $\begin{array}{l}\text { Bending } \\
\text { moment in } \\
\text { tower } \\
(\mathrm{kN}-\mathrm{m})\end{array}$ & $\begin{array}{l}225993 \\
(100 \%)\end{array}$ & $\begin{array}{c}299681 \\
(32.61 \%)\end{array}$ & $\begin{array}{c}228578 \\
(1.14 \%)\end{array}$ & $\begin{array}{c}297890 \\
(31.81 \%)\end{array}$ & $\begin{array}{c}211325 \\
(-6.49 \%)\end{array}$ \\
\hline
\end{tabular}

structural stiffness of each of the four components, i.e. main cable, hangers, main girder, and bridge tower, was reduced by half. It is shown that by reducing the stiffness by half, the ultimate load-bearing capacity of the whole bridge is most seriously affected by the main cable; next are the hangers, main girder and bridge, respectively.

For explain purposes, the effects on the internal forces in the suspension bridge due to a reduction of structural stiffness in the substructures is shown in Table 4 for the case of the load-bearing coefficient being $L=2.0$. The table indicates that, due to reduction of the stiffness, the main cable among the substructures produced the highest increase in force of the hangers. The next severe case is the hangers, and then the main girder, and finally the tower. For the original structure, the final failure of the whole suspension bridge occurred when the stress in the mid-span hanger reached the ultimate strength; it can be concluded that the reduction of stiffness by half will affect the ultimate load-bearing capacity of the suspension bridge most severely by the main cable, and then by the hangers, and then by the main girder, and finally by the bridge tower.

\section{2) Effects on the Failure Process}

When the stiffness of the main cable was reduced by half, the stress of the No. 28 hanger reached the yield stress value at $L=2.65$; when $L=2.73$, a plastic hinge was formed in the tower next to the bottom edge of the main girder at the towergirder connection; and when $L=2.81$, the stress of the No. 28 hanger reached the ultimate stress value and the whole suspension bridge failed.

When the stiffness of the hanger was reduced by half, the stress of the No. 28 hanger reached the yield stress value at $L=2.82$; and when $L=3.01$, the stress of the same hanger reached the ultimate stress value and the whole suspension bridge failed.

When the stiffness of the main girder was reduced by a half, the stress of the No. 28 hanger reached the yield stress value at $L=2.61$; when $L=2.95$, a plastic hinge started to form in the main girder near the tower-girder connection; and when $L=$ 3.09 , the stress of the No. 28 hanger reached the ultimate stress value and the whole suspension bridge failed.

When the stiffness of the tower was reduced by a half, the stress of the No. 28 hanger reached the yield stress value at $L=2.73$; when $L=3.14$, a plastic hinge was formed in the concrete of the tower near the tower-girder connection; and when $L=3.17$, the stress of the No. 28 hanger reached the ultimate stress value and the whole suspension bridge failed.

\section{The Effects of Broken Hangers on the Load-Carrying Coefficient}

Table 5 shows the effects of broken hangers at various locations on the ultimate load-bearing coefficient of the selfanchored suspension bridge. It is revealed that the closer the broken hanger is to the mid-point of the main span, the greater the effect it has on the bridge. This is easily understood, because for the original structure the whole bridge failed when the stress in the mid-span hanger reached the ultimate stress level. Thus, a broken hanger near the mid-span would cause the stress in the mid-span hanger to increase and reaching the yield stress and the ultimate stress early, which eventually lead to the failure of the bridge.

Table 6 shows the effect of simultaneous breakage of hangers at different locations on the ultimate load-bearing coefficient of the self-anchored suspension bridge. Case 1 shows the effect when the mid-span hanger and the two side hangers broke in the indicated sequence. On the other hand, Case 2 shows the effect when the hangers on either side of the mid-span hanger broke in the indicated sequence. Lastly, Case 3 shows the effect when the hangers on either side of the mid-span hanger broke in an alternative sequence.

For Case 2, when the six pairs of hangers, i.e. 25, 26, 27, 29, 30,31 , broke simultaneously, the ultimate load-bearing coefficient of the bridge was less than 1.0 and the bridge failed 
Table 5. Effect of broken hanger at various locations on the ultimate load-bearing coefficient.

\begin{tabular}{cc}
\hline No of broken hanger & Ultimate load-bearing coefficient \\
\hline 19,37 & 3.18 \\
20,36 & 3.18 \\
21,35 & 3.13 \\
22,34 & 3.09 \\
23,33 & 3.01 \\
24,32 & 2.92 \\
25,31 & 2.87 \\
26,30 & 2.65 \\
27,29 & 2.30 \\
28 & 2.85 \\
\hline
\end{tabular}

Table 6. Effect of simultaneous breakage of hanger at different locations on the ultimate load-bearing coefficient.

\begin{tabular}{ccc}
\hline Item & Broken hanger number & Ultimate load-bearing \\
\hline & 28 & 2.85 \\
Case 1 & $27,28,29$ & 2.13 \\
& $26,27,28,29,30$ & 1.72 \\
& $25,26,27,28,29,30,31$ & 1.29 \\
& $24,25,26,27,28,29,30,31,32$ & Less than 1.0 \\
\hline \multirow{3}{*}{ Case 2} & 27,29 & 2.30 \\
& $26,27,29,30$ & 1.48 \\
& $25,26,27,29,30,31$ & Less than 1.0 \\
\hline \multirow{3}{*}{ Case 3} & 27,29 & 2.30 \\
& $23,25,27,29,31,33$ & 1.94 \\
& $21,23,25,27,29,31,33,35$ & 1.84 \\
& $19,21,23,25,27,29,31,33,35,37$ & 1.84 \\
\hline
\end{tabular}

immediately under its own weight. Furthermore, it is shown for Case 2 that the effect was most prominent when the hangers on either side of the mid-span hanger broke subsequently.

\section{CONCLUSIONS}

The results of this investigation can be summarized as follows:

(1) For the self-anchored suspension bridge considered herein, after load $P=(L-1) P_{d}$ was applied to the main girder and as $L$ gradually increased, the concrete gradually cracked at the top of the main girder near the tower-girder connection, at the bottom of the main girder in the main span, at the bottom of the tower, and at the tower near the tower-girder connection. When the stress in the No. 28 hanger located at the mid-point of the main span reached its ultimate stress, the whole bridge collapsed.
(2) For the original structure, the whole suspension bridge failed when the stress in the hanger at the mid-span reached its ultimate stress, so among the effect on the ultimate load-bearing capacity of the whole suspension bridge when the strength of each of the four substructures of the self-anchored suspension bridge (i.e. main cable, hangers, main girder, and tower) was reduced by half, that the strength of the hanger was reduced was the most severe case. Next was the reduction in strength of the main cable, and then the main girder, and the finally the tower. In the case of stiffness reduced by half, the main cable affected the ultimate load-bearing capacity of the whole bridge most seriously. Next was the reduction in stiffness of the hangers, and then the main girder, and the finally the tower. For the broken hangers, the closer the broken hanger was to the mid-point of the main span, the larger the effect it had on the ultimate load-bearing capacity of the whole bridge. The effect was most prominent when the hangers on either side of the mid-span hanger broke subsequently. When the six pairs of the hangers (i.e 25, 26, $27,29,30,31)$ broke simultaneously, the ultimate loadbearing coefficient of the bridge was less than 1.0 and the bridge failed immediately under its own weight.

\section{REFERENCES}

1. Cheng, J. and Jiang, J. J., "Ultimate behavior of long-span steel arch bridges," Structural Engineering and Mechanics, Vol. 14, No. 3, pp. 331343 (2002).

2. Feng, L. C., Wang, H., and Zhao, R. D., "Geometrical and material nonlinear analysis of force behaviors in a large-span reinforced concrete archbridge," Technology of Highway and Transport, No. 3, pp. 20-26 (2000).

3. Jiang, M., Qiu, W. L., and Han, L. H., "Ultimate load-carrying capacity of self-anchored concrete suspension bridge," Proceedings of the 34th conference on Our World in concrete \& Structures, Singapore, August, pp. 139-145 (2009).

4. Kao, C. S. and Kou, C. H., "The influence of broken cables on the structural behavior of long-span cable-stayed bridges," Journal of Marine Science and Technology, Vol. 18, No. 3, pp. 395-404 (2010).

5. Komatsu, S. and Sakimoto, T., "Ultimate load-carrying capacity of steel arches," Journal of the Structural Division, ASCE, Vol. 103, No. ST12, pp. 2323-2336 (1977).

6. Pan, J. Y., Jang, G. J., and Cheng, Q. G., "Geometrical and material nonlinear analysis for determining ultimate load capacity of long-span bridges," China Civil Engineering Journal, Vol. 33, No. 1, pp. 5-8 (2000).

7. Ren, W. X., "Ultimate behavior of long-span cable-stayed bridge," Journal of Bridge Engineering, ASCE, Vol. 4, No. 1, pp. 30-37 (1999).

8. Seif, S. P. and Dilger, W. H., "Nonlinear analysis and collapse load of p/c cable-stayed bridges," Journal of Structural Engineering, ASCE, Vol. 116, No. 3, pp. 829-849 (1990).

9. Shiu, F. M., Ultimate Load-Bearing Analysis of Medium- and Large-Span Cable-Stayed Bridges, Master Thesis, Graduate Institute of Civil Engineering, Chung Hua University, Hsinchu, Taiwan (2003).

10. Wang, J. J., Yang, W. H., and Liu, G. D., "The geometrical nonlinear analysis of large-span suspension bridges," Journal of Hunan University, Vol. 25, No. 3, pp. 70-73 (1998).

11. Ye, J. M., Structural Plastic Analysis of a Increment Stiffness Method Cable-Stayed Bridge, Master Thesis, Graduate Institute of Civil Engineering, Chung Yuan Christian University, Taoyuan, Taiwan (2006). 